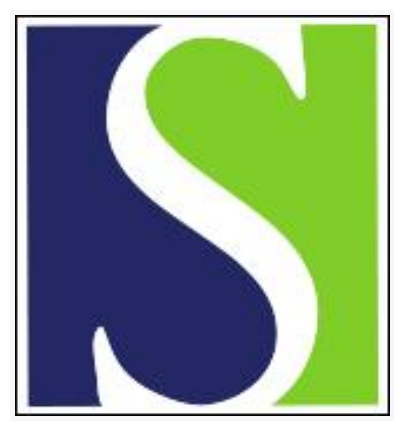

Scand J Work Environ Health 1998;24(5):398-406

https://doi.org/10.5271/sjweh.361

Issue date: Oct 1998

Occupational skin and respiratory diseases among hairdressers

by Leino T, Tammilehto L, Hytönen M, Sala E, Paakkulainen H, Kanerva L

Key terms: allergy; asthma; atopy; dermatitis; koilonychia; laryngitis; prevalence; rhinitis

This article in PubMed: www.ncbi.nlm.nih.gov/pubmed/9869312

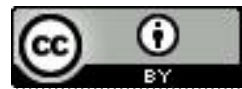




\title{
Occupational skin and respiratory diseases among hairdressers
}

\author{
by Timo Leino, MD, ${ }^{1}$ Lauri Tammilehto, MD, ${ }^{2}$ Maija Hytönen, MD, ${ }^{3}$ Eeva Sala, MD, ${ }^{4}$ Harri Paakkulainen, \\ MSc, ${ }^{2}$ Lasse Kanerva, MD'
}

\begin{abstract}
Leino T, Tammilehto L, Hytönen M, Sala $E$, Paakkulainen H, Kanerva L. Occupational skin and respiratory diseases among hairdressers. Scand J Work Environ Health 1998;24(5):398-406.

Objectives The occurrence and causes of hairdressers' occupational skin and respiratory diseases were studied. Methods Of a random sample of 500 female hairdressers aged 15-54 years, 355 were available for study. Of the 189 reporting work-related skin and respiratory symptoms in a computer-aided telephone interview on exposure and health, 130 underwent a physical examination, lung function tests, prick and patch testing, and nasal and lung provocation tests. An occupational disease was diagnosed when the causality between exposure and disease was probable and the clinical tests supported the diagnosis.

Results The telephone interview revealed a life-time prevalence of $16.9 \%$ for hand dermatoses, $16.9 \%$ for allergic rhinitis, and $4.5 \%$ for asthma among the hairdressers. In the clinical investigations, the prevalence was $2.8 \%$ for occupational dermatoses, $1.7 \%$ for occupational rhinitis, and $0.8 \%$ for occupational asthma. Ammonium persulfate caused $90 \%$ of the respiratory diseases and $27 \%$ of the hand dermatoses. Paraphenylenediamine, natural rubber latex, and skin irritation were also causes of hand dermatitis. Allergy to human dandruff (8.6\%) and Pityrosporum ovale $(12.1 \%)$ was common. Previously diagnosed atopic diseases increased the risk for occupational skin or respiratory disease 3 -fold (odds ratio $2.9,95 \%$ confidence interval $1.1-7.9$ ). Of the cases, $37.5 \%$ (6 of 16 persons) had to change occupations during a 3-year follow-up.

Conclusions Work-related skin and respiratory symptoms are common among hairdressers. Often a specific cause (eg, ammonium persulfate) can be found if occupational diseases are suspected and diagnosed. Hairdressers with atopic diseases are at risk of developing occupational skin and respiratory diseases.
\end{abstract}

Key terms allergy, asthma, atopy, dermatitis, koilonychia, laryngitis, prevalence, rhinitis.

Several reports on hairdressers' occupational skin diseases have been published on the basis of patient materials of specialist clinics $(1-5)$. Due to the selective patient material of the clinics, it is difficult, however, to draw conclusions on the prevalence of occupational diseases in the profession as a whole. Register data on occupational diseases are also available, but they are inaccurate for many reasons (6). The variety of the definition of occupational diseases and the exposure situations make international comparison difficult (6).

According to the national register of occupational diseases maintained by the Finnish Institute of Occupational Health, the annual prevalence of occupational skin diseases among female hairdressers is $20-40$ cases per 10000 working people (6). The figure is low in comparison with that of Germany, where the corresponding figure was reported to be 244 cases per 10000 working people (7). A comparison between these figures is difficult due to differences in data collection, but it is likely that the number of reported occupational diseases among hairdressers in Finland is an underestimate.

Little information is available on the prevalence of occupational respiratory diseases among hairdressers. According to data from the Finnish register of occupational diseases, the annual prevalence of occupational asthma is 4 cases for every 10000 hairdressers. To the best of our knowledge, estimates of the prevalence of occupational respiratory diseases among hairdressers in other countries have not been published.

In the present work we have studied the occurrence and causes of hairdressers' occupational skin and respiratory diseases in an unselected material.

Department of Occupational Medicine, Finnish Institute of Occupational Health, Helsinki, Finland.

Department of Epidemiology and Biostatistics, Finnish Institute of Occupational Health, Helsinki, Finland.

Department of Otorhinolaryngology, Helsinki University Hospital, Helsinki, Finland.

Department of Otorhinolaryngology, Turku University Hospital, Turku, Finland.

Reprint requests to: Dr Timo Leino, Finnish Institute of Occupational Health, Topeliuksenkatu 41 a A, FIN-00250 Helsinki, Finland. [E-mail: tile@occuphealth.fi] 


\section{Subjects and methods}

The study population comprised female hairdressers aged 15-54 years and presently working in the Helsinki metropolitan area with a population of about 900000 . Only women were selected for the study because $96 \%$ of the 12000 hairdressers in Finland are women. A stratified disproportionate random sample of 500 female hairdressers in 5-year age groups was drawn from the trade union. membership registers. After 60 subjects were removed who had not been working as a hairdresser within 3 months before the study, the final sample consisted of 440 hairdressers. A computer-aided telephone interview was used to collect data (9). After removing the 61 hairdressers whose telephone number was not traceable, the 10 who refused to participate, and the 15 who could not be contacted, we were left with 355 complete interviews. The interviews were performed in February-April 1994; they included questions about diseases diagnosed by a physician, respiratory and skin symptoms and their duration, and worktasks that aggravated the respiratory and skin symptoms (10).

Hairdressers reporting work-related skin or respiratory symptoms $(\mathrm{N}=189)$ were invited to a structured computer-aided occupational medical interview and physical examination. After 1 reminder, 130 participated. The nonrespondents were contacted by phone and asked the reason for their nonparticipation. As the most common reasons for their nonparticipation, the women stated that the symptoms were mild or had disappeared, that they had changed occupation, or that they had difficulty finding time.

The interview charted the subjects' work history, current work, exposure to hairdressing chemicals, atopy, living habits, symptoms and diseases, medication, previous medical examinations, and use of protective equipment. Samples of the most generally used protective gloves, made of polyvinyl chloride, polyethylene, or natural rub- ber latex, were available to help the subjects recognize the types of gloves they had been using. The interviewees were asked to assess the extent to which an individual symptom had affected their work ability on a scale ranging from 1 (not at all) to 5 (very much). In the final analysis grades 4 and 5 were combined to represent marked difficulties to work.

The suspected cases of occupational disease $(\mathrm{N}=109)$ were selected for further clinical examination. For selection a person had to have skin or respiratory symptoms indicating hand dermatosis, rhinitis, laryngitis, or asthma. The symptoms had to start or worsen at work and had to be associated with a specific work factor. Depending on their symptoms, the hairdressers were directed for examination to an occupational dermatologist, an otorhinolaryngologist, a phoniatrist, or a pulmonologist.

A structured computer-aided interview was used to ensure that the occupational medical interviews would be uniform in quality. All the initial examinations were performed by the same physician (TL). The actual clinical examinations to reveal occupational diseases were only started when the examining physician and another specialist in occupational medicine, not otherwise involved in the study, agreed on the suspicion of an occupational disease.

The age distribution, frequency of atopic diseases, and smoking habits of the study groups are given in table 1 . The youngest age group (16-24 years) was overrepresented in the nonsymptom group. The proportion of persons with a diagnosed atopic disease was highest $(55 \%)$ in the clinical study group $(\mathrm{N}=109)$ and lowest $(23.8 \%)$ in the nonsymptom group $(\mathrm{N}=166)$. Smoking habits did not vary between the various groups, and about half of each group smoked.

Of the 130 interviewed subjects, 123 were tested for atopy by defining the Phadiatop ${ }^{\circledR}$ count (Pharmacia \& Upjohn, Sweden). Values over $0.35 \mathrm{IU} / 1$ were considered positive. In the case of suspected occupational

Table 1. Personal characteristics of the study groups of hairdressers. (CATI = computer-aided telephone interviews)

\begin{tabular}{|c|c|c|c|c|c|}
\hline Characteristic & $\begin{array}{c}\text { CATI } \\
\text { group } N=355 \\
(\%)\end{array}$ & $\begin{array}{c}\text { Symptomatic } \\
\text { group } N=189 \\
(\%)\end{array}$ & $\begin{array}{c}\text { Nonsymptomatic } \\
\text { group } N=166 \\
(\%)\end{array}$ & $\begin{array}{l}\text { Clinical interview } \\
\text { group } N=130 \\
(\%)\end{array}$ & $\begin{array}{c}\text { Clinical study } \\
\text { group } N=109 \\
(\%)\end{array}$ \\
\hline \multicolumn{6}{|l|}{ Age (years) } \\
\hline $\begin{array}{l}16-24 \\
25-34 \\
35-44 \\
45-55\end{array}$ & $\begin{array}{l}25.3 \\
42.8 \\
17.5 \\
14.4\end{array}$ & $\begin{array}{l}19.6 \\
49.2 \\
16.9 \\
14.3\end{array}$ & $\begin{array}{l}31.9 \\
35.5 \\
18.1 \\
14.5\end{array}$ & $\begin{array}{l}16.2 \\
48.5 \\
19.2 \\
16.1\end{array}$ & $\begin{array}{l}16.5 \\
46.8 \\
20.2 \\
16.5\end{array}$ \\
\hline \multicolumn{6}{|l|}{ Atopya } \\
\hline $\begin{array}{l}\text { Own judgment } \\
\text { Diagnosed }\end{array}$ & $\begin{array}{l}43.4 \\
33.4\end{array}$ & $\begin{array}{l}53.5 \\
42.8\end{array}$ & $\begin{array}{l}32.5 \\
23.8\end{array}$ & $\begin{array}{l}56.3 \\
50.8\end{array}$ & $\begin{array}{l}59.3 \\
55.0\end{array}$ \\
\hline \multicolumn{6}{|l|}{ Smoking } \\
\hline $\begin{array}{l}\text { Never smoker } \\
\text { Ex-smoker } \\
\text { Current }\end{array}$ & $\begin{array}{l}41.7 \\
11.0 \\
47.3\end{array}$ & $\begin{array}{l}41.8 \\
10.6 \\
47.6\end{array}$ & $\begin{array}{l}41.6 \\
11.4 \\
47.0\end{array}$ & $\begin{array}{l}41.5 \\
13.1 \\
45.4\end{array}$ & $\begin{array}{l}38.5 \\
12.9 \\
48.6\end{array}$ \\
\hline
\end{tabular}

a Asthma or allergic rhinitis or atopic dermatitis diagnosed by a physician or according to the subject's own judgment. 
respiratory or skin disease, skin prick tests were performed with 21 common environmental allergens and 8 hairdressers' allergens and scored routinely (11). Patients referred to the clinic and occupationally unexposed to human dandruff and Pityrosporum ovale were used as referents for the hairdressers. The test was done on the volar aspect of the forearm. The result was read as the mean of the longest diameter of the weal and the diameter perpendicular to it. A weal of $\geq 3 \mathrm{~mm}$ in diameter and equal to or greater than half of the histamine hydrochloride $(10 \mathrm{mg} / \mathrm{ml})$ weal was defined as positive, indicating sensitization (12). In cases of suspected occupational eczema, patch tests were conducted by Finn chamber ${ }^{\circledR}$ tests (13) with a modified European standard series (30 chemicals), a hairdressers' series ( 15 chemicals), and a combined cosmetic, preservative, and perfume series (29 chemicals). The hairdressers' own chemicals from their work were tested when they were suspected to cause the symptoms. The tests were scored when the patches were removed ( 48 hours), and also 24 and 48-120 hours later (ie, 3 readings). The tests were scored according to the recommendations of the International Contact Dermatitis Research Group (14). Cutaneous reactions rated 1+, $2+$, and $3+$ were considered allergic.

The lung function tests included spirometry, a bronchodilatation test, and histamine challenge. They were done for the subjects who had respiratory symptoms. Spirometry was performed with a computer-connected dry piston device (Medicro, Kuopio, Finland, or Vicatest 300, Mijnhardt, Holland) using the spirometric reference values of Viljanen et al (15). Three doses of rimiterol $(0.2 \mathrm{mg} / \mathrm{dose})$ were used in the bronchodilatation test. The bronchodilator response was obtained when the improvement in forced expiratory volume in 1 second $\left(\mathrm{FEV}_{1.0}\right)$ was more than $15 \%$ of the predicted value, and it exceeded $200 \mathrm{ml}$ (16). The method of Sovijärvi et al, using a Spira electro 2 device (Spira, Helsinki, Finland), was used for the histamine challenge (17). The reaction was reported as a $\mathrm{PD}_{15}$ value (ie, the histamine dose that caused a $15 \%$ decrease in $\mathrm{FEV}_{1.0}$ ).

Nine hairdressers with asthmatic symptoms in conjunction with specific work exposure underwent a 2-week peak expiratory flow (PEF) follow-up at work (18). In 10 cases a lung provocation test in a provocation chamber with a suspected chemical, usually with the subject's own bleaching powder, was used for the final verification of occupational asthma (19). A 20\% decrease in the $\mathrm{FEV}_{1.0}$ or peak expiratory flow (PEF) was considered diagnostic for asthma. A placebo test, usually with lactose, was used to overrule nonspecific bronchial responsiveness.

Nasal provocation tests with an aqueous solution of the suspected chemical, usually with $0.1 \%$ ammonium persulfate, $0.6 \%$ ammonium thioglycolate, and $75 \mu \mathrm{g} / \mathrm{ml}$ of human dandruff extract were performed for 79 hair- dressers with upper respiratory tract symptoms. The human dandruff extract was prepared according to the method of $\mathrm{Yu}$ et al (20). The same extract was used both in the nasal provocation tests and in the skin prick tests. The result of the nasal provocation test was considered positive according to earlier published criteria (21); in short, an essential change in the swelling of the mucous membrane should have occurred or there should have been an increase in secretion during the provocation. The results of the provocation tests of the suspected laryngitis cases (39 hairdressers) were judged according to the criteria of Sala et al (22).

The participation in the telephone interviews and examinations was voluntary. The written consent of the patients was obtained for the clinical examinations. The study was approved by the ethical committee of the Finnish Institute of Occupational Health. Logistic regression was used to estimate the odds ratios (OR) for occupational skin or respiratory disease and their $95 \%$ confidence intervals $(95 \% \mathrm{CI})$. The variables used in the model were diagnosed atopic disease in the subject's medical history, age, and time in occupation. All the calculations were performed with the SAS statistical package (23).

\section{Results}

Of the 355 telephone-interviewed hairdressers, 189 $(53 \%)$ reported work-related skin and respiratory symptoms, and $130(69 \%)$ of the 189 came for the occupational medical interview (figure 1). On the basis of the interview and physical examination, $109(84 \%)$ met the criteria for suspected occupational disease. The distribution of work-related symptoms among the nonparticipants $(\mathrm{N}=59)$ was as follows: 46 with rhinitis, 22 with hoarseness, 16 with cough, 7 with dyspnea, and 11 with hand dermatitis. The 2 asthma cases among the nonparticipants were verified from the medical records as nonoccupational. We did not find any occupational skin or respiratory diseases reported in the register of occupational diseases among the nonparticipants.

In the telephone interview more than half of the subjects reported that their respiratory symptoms worsened at work (table 2). Hair bleaching and the use of aerosol hair sprays were regarded as the most provocative factors to increase the respiratory symptoms. Of the 60 hairdressers reporting hand eczema, $75 \%$ believed that it got worse at work. The application of permanent wave solutions and the washing of clients' hair were the most often mentioned causes of worsening hand dermatitis.

In the occupational medical interview dyspnea, thinitis, and hand eczema were reported to cause marked difficulties to work (table 3). Although about one-third of the hairdressers also had work-related cough and hoarseness, they did not believe that these symptoms 


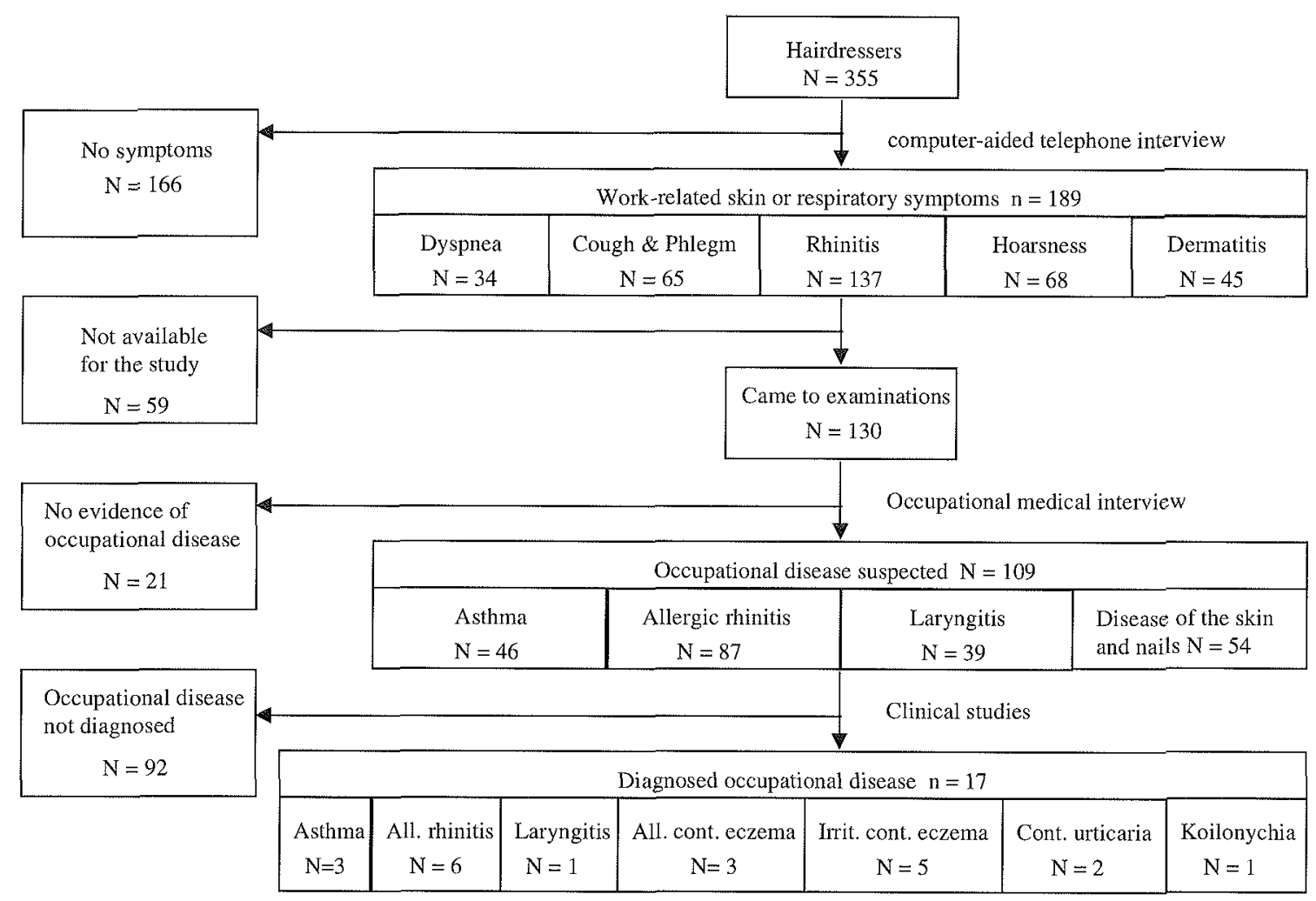

Figure 1. Flow chart of the study. The numbers of individual symptoms, suspected cases of occupational diseases, and diagnosed occupational diseases do not correspond to the number of persons since a single subject could have several symptoms and findings. $($ All $=$ allergic, cont $=$ contact, Irrit = irritative)

Table 2. Respiratory and skin symptoms of the hairdressers $(\mathrm{N}=355)$ and their relation to worktasks in the computer-aided telephone interviews.

\begin{tabular}{|c|c|c|c|c|c|}
\hline \multirow[t]{2}{*}{ Symptom } & \multicolumn{2}{|c|}{$\begin{array}{l}\text { Persons with } \\
\text { symptoms }\end{array}$} & \multicolumn{2}{|c|}{$\begin{array}{l}\text { Persons relating } \\
\text { symptoms to work }\end{array}$} & \multirow[t]{2}{*}{$\begin{array}{l}\text { Worktasks making } \\
\text { the symptoms worse } \\
\text { cid }\end{array}$} \\
\hline & N & $\%$ & N & $\%$ & \\
\hline Cough and phlegm & 127 & 35.9 & 65 & 18.8 & Bleaching, lacquering, giving permanents, dyeing \\
\hline Dyspnea & 57 & 16.1 & 34 & 9.7 & Lacquering, bleaching, giving permanents, dyeing \\
\hline Rhinitis & 221 & 62.6 & 137 & 39.9 & Bleaching, lacquering, giving permanents, dyeing \\
\hline Hoarseness & 105 & 29.9 & 68 & 19.7 & Bleaching, lacquering, giving permanents, dyeing \\
\hline Hand eczema & 60 & 16.9 & 45 & 12.7 & Giving permanents, washing, bleaching, dyeing \\
\hline
\end{tabular}

a Based on the question: "Do you have (the symptom)?"

"Based on the question: "Is the symptom you reported related to your work?"

"Based on the question: "What worktasks have made (the symptom) worse?"

a In order of frequency.

compromised their work ability as often as the 3 firstmentioned causes. Different medications were used widely. Every 3rd hairdresser (51 of 130) had sometimes taken medication for allergic rhinitis, every 4 th (32 of 130) had used corticosteroid creams for hand eczema, and 1 in 20 ( 7 of 130) used asthma medication.

The hairdressers' tasks varied considerably. The median was 6 (range 2-15) hair cuts per day. Hair finishing products (lacquer, gel, mousse, foam) were used on almost every hairdo. The median per week was 8 (range 0 -30) for dye treatments, 5 (range $0-23$ ) for giving permanents, and 3 (range $0-14$ ) for bleach treatments.
Table 3. Number of hairdressers reporting marked difficulties (grades 4 \& 5) to work. $^{\text {a }}$

\begin{tabular}{lrr}
\hline Symptom & \multicolumn{2}{c}{ Hairdressers $(N=130)$} \\
\cline { 2 - 3 } & \multicolumn{1}{c}{$N$} & $\%$ \\
\hline Rhinitis & 18 & 13.8 \\
Dyspnea & 10 & 7.7 \\
Cough & 3 & 2.3 \\
Hoarseness & 3 & 2.3 \\
Hand eczema & 16 & 12.3 \\
\hline
\end{tabular}

a Based on the question: "Has the symptom affected your work ability: 1 $=$ not at all, $2=$ slightly, 3 = to some extent, $4=$ much, or $5=$ very much?" 
Ninety percent of the hairdressers used protective gloves in hair dyeing and bleaching jobs, but only $3 \%$ during hairwashing. In addition, $56 \%$ gave permanents without protective gloves. Polyvinyl chloride and polyethylene gloves were used the most frequently in all hair treatments. The use of gloves of natural rubber latex was highest in hair dyeing (9\%). Seventy-five percent reported that their hands were moist or wet during more than half of their workday. Altogether $70 \%$ washed their hands more than 10 times a day, and $25 \%$ washed them more than 20 times a day with water and shampoo, liquid or bar soap, or a special washing liquid.

In the lung function tests, spirometry was within the age- and gender-related reference values for all 89 of the hairdressers examined for respiratory symptoms. Five subjects had positive results in the bronchodilatation test, and 17 subjects (19\%) had bronchial hyperreactivity, of which 1 case was strong, 3 were moderate, and 13 were mild.

Nine of the lung provocation tests were positive, indicating occupational asthma. The nasal provocation tests

Table 4. Prick test results (107 hairdressers tested). (ALK = Allergologisk Laboratorium A/S, Copenhagen, Denmark; Armi = glove trademark; $\mathrm{FIOH}=$ prepared at the Finnish Institute of Occupational Health)

\begin{tabular}{|c|c|}
\hline Allergen & Positive reactions $(\mathrm{N})$ \\
\hline \multicolumn{2}{|l|}{ Standard series } \\
\hline Histamine hydrochloride $10 \mathrm{mg} / \mathrm{ml}$ & 103 \\
\hline Negative control (standard) & 1 \\
\hline Birch 10 HEP (ALK) & 21 \\
\hline Alder 10 HEP (ALK) & 16 \\
\hline Meadow fescue 10 HEP (ALK) & 13 \\
\hline Timothy 10 HEP (ALK)) & 12 \\
\hline Ragweed 10 HEP (ALK) & 11 \\
\hline Dandelion 1:100 (ALK) & 4 \\
\hline Horse 1:100 (ALK) & 8 \\
\hline Cow 1:100 (ALK) & 5 \\
\hline Cat $1: 100(A L K)$ & 15 \\
\hline Dog $1: 100($ ALK) & 16 \\
\hline Lamb's wool 1:100 & 1 \\
\hline Chicken feather 1:100 & 1 \\
\hline$D$ farinae 10 HEP (ALK) & 4 \\
\hline$D$ pteronissius $10 \mathrm{HEP}$ (ALK) & 5 \\
\hline Alternaria alternata (tenuis) $1: 20$ (ALK) & 2 \\
\hline Cladosporium herbarum $1: 20$ (ALK) & 1 \\
\hline Household glove (Armi) & 2 \\
\hline Latex glove (FIOH) & 1 \\
\hline Willow 1:100 (ALK) & 3 \\
\hline Natural rubber (latex) 1:100 (ALK) & 3 \\
\hline Pityrosporum ovale 1:20 (ALK) & 12 \\
\hline \multicolumn{2}{|l|}{ Hairdressers' series } \\
\hline Histamine hydrochloride $10 \mathrm{mg} / \mathrm{ml}$ & 107 \\
\hline Negative control (standard) & 1 \\
\hline Negative control (Bencard) & - \\
\hline Coca-glycerol control (FIOH) & - \\
\hline Phosphate-glycerol control (F|OH) & - \\
\hline Disperse violet $4 \%$ (FIOH) & - \\
\hline Pigment blue $\mathrm{Cl} 77007$ (FlOH) & - \\
\hline Human dandruff extract $75 \mu \mathrm{g} / \mathrm{ml}(\mathrm{FIOH})$ & 3 \\
\hline Human dandruff extract $150 \mu \mathrm{g} / \mathrm{ml}(\mathrm{F} / \mathrm{OH})$ & 3 \\
\hline Human dandruff extract (Bencard) & 5 \\
\hline Ammonium persulfate $2 \%$ ( $\mathrm{FlOH})$ & 3 \\
\hline Potassium persulfate $2 \%(\mathrm{~F} \mid \mathrm{OH})^{\prime}$ & 4 \\
\hline Ammonium thioglycolate $10 \%(\mathrm{~F} \mid \mathrm{OH})$ & - \\
\hline
\end{tabular}

with ammonium thioglycolate were all negative. Those with human dandruff gave inconsistent reactions when compared with the results of the skin prick tests. The nasal provocation test with ammonium persulfate was positive in 6 cases.

The Phadiatop® was positive for $26 \%$ of the examined 123 hairdressers. In the skin prick tests (table 4), 3 hairdressers reacted to ammonium persulfate, 4 to potassium persulfate, 7 to human dandruff, 12 to $P$ ovale, and 3 to natural rubber latex. All told, $8.6 \%$ of the hairdressers ( 7 of 81 ) reacted to human dandruff and $12.1 \%$ (12 of 99$)$ to $P$ ovale, the corresponding figures being $0.3 \%$ ( 1 of 311 ) and $3.5 \%$ (26 of 711 ) for the referents. The patch tests yielded 1 occupationally relevant, delayed allergic reaction to ammonium persulfate and 2 to paraphenylenediamine (table 5). Nickel sulfate and cobalt chloride were the most frequent sensitizers. The relevance of these reactions for hairdressing is questionable. Single, occupationally nonrelevant reactions were detected against the following 7 substances: chloroacetamide, pyrocatechol, toluene disulfonamide formaldehyde resin, Amercol L 101®, oleamidopropyldimethylamine, cocamidopropylbetadine, and oak moss. One case of contact urticaria from ammonium persulfate was verified in an open test, and one caused by natural rubber latex was found in a use test.

In the telephone interview, $13.8 \%(\mathrm{~N}=49)$ of the hairdressers reported that they had suffered from hand dermatitis and 2.8\% $(\mathrm{N}=10)$ from asthma within the past 12 months. The life-time prevalence was $16.9 \%(\mathrm{~N}=60)$ for dermatoses and $4.5 \%$ for asthma $(N=16)$. Allergic rhinitis was diagnosed for $16.9 \%(\mathrm{~N}=60)$ of the hairdressers. The clinical investigations revealed occupational skin and respiratory diseases in 17 hairdressers (table 6). The prevalence was $2.8 \%$ for occupational dermatoses (11 of 355), $1.7 \%$ for occupational rhinitis ( 6 of 355 ), and $0.8 \%$ for occupational asthma ( 3 of 355 ). In the group which considered their symptoms work-related, an occupational disease could be diagnosed for $11.1 \%$ (21 of 189), and for the group suspected of occupational disease after the assessment by specialists in occupational medicine the corresponding figure was $19.3 \%$ (21 of 109).

Three cases of asthma, 6 cases of allergic rhinitis, and 1 case of laryngitis were diagnosed as occupational respiratory diseases. Eleven cases of occupational diseases of the skin and fingernails were diagnosed, 3 of which were allergic contact dermatitis, 5 of which were irritant contact dermatitis, 2 of which were contact urticaria, and 1 of which was koilonychia caused by permanent wave solutions. One case of asthma and 1 of dermatitis had previously been diagnosed as an occupational disease. Altogether $90 \%$ of the occupational respiratory diseases were caused by ammonium persulfate in bleaches. One case of occupational asthma was caused by permanent wave solutions. Five cases of dermatitis were caused by 
Table 5. Patch test results in the standard series and in the hairdressers' series (54 hairdressers tested).

\begin{tabular}{|c|c|}
\hline Allergen & Positive reactions (N) ${ }^{\mathrm{a}}$ \\
\hline \multicolumn{2}{|l|}{ Standard series } \\
\hline Potassium chromate & - \\
\hline Paraphenylenediamine (base) & 2 \\
\hline Thiuram mix & - \\
\hline Neomycin sulfate & 4 \\
\hline Cobalt chloride & 7 \\
\hline Caine mix & - \\
\hline Nickel sulfate & 19 \\
\hline Quinoline mix & - \\
\hline Colophony & 1 \\
\hline Parabens & - \\
\hline Rubiper mix & - \\
\hline Wool alcohols & - \\
\hline Mercapto mix & - \\
\hline Epoxy resin & 1 \\
\hline Balsam of Peru & 3 \\
\hline Fragrance mix & 2 \\
\hline Triethylene glycol diacrylate & - \\
\hline Formaldehyde & - \\
\hline Sesquiterpenelactone mix & - \\
\hline$p$-tert-Butylphenol formaldehyde resin & - \\
\hline Quaternium 15 & - \\
\hline Terpene peroxides & - \\
\hline Budesonide & - \\
\hline Bacitrasin & - \\
\hline Tixocortol-21-pivalate & - \\
\hline Dequalone chloride & 1 \\
\hline Setostearol & - \\
\hline Mercaptobenzothiazole & - \\
\hline Sorbitanesesquioleate & - \\
\hline Cl+Me-isothiazolinone & 2 \\
\hline \multicolumn{2}{|l|}{ Hairdressers' series } \\
\hline 2,5-Diaminotoluene sulfate & - \\
\hline 2-Nitro-4-phenylenediamine & - \\
\hline Ammonium thioglycolate & - \\
\hline Resorcinol & - \\
\hline 3-Aminophenol & - \\
\hline Hydrogen peroxide & - \\
\hline chloroacetamide & 1 \\
\hline Glyceryl monothiogylcolate & - \\
\hline 4-Aminodiphenylamine & - \\
\hline Ammonium persulfate & 1 \\
\hline 4-Aminophenol & - \\
\hline Pyrogallol & - \\
\hline Hydroquinone & - \\
\hline 4-Aminoazobenzene & - \\
\hline Pyrocatecol & 1 \\
\hline
\end{tabular}

${ }^{\text {a }}+1,+2$ and +3 allergic reactions.

the skin irritation of hairdressing chemicals. The cause of allergic contact dermatitis was paraphenylenediamine (PPDA) in hair dyes in 2 cases and ammonium persulfate in 1 case. One case of contact urticaria was caused by ammonium persulfate in bleaching powders and 1 case by natural rubber latex from protective gloves.

The women diagnosed as having an occupational disease averaged 39 (range 23-55) years of age and had spent an average of 17 (range 3.5-34) years in the hairdressing business. Exposure to hairdressing chemicals averaged $9(0.5-20)$ years. The time in the occupation and the exposure time did not differ notably between the women with and the women without an occupational disease. Neither was there a marked difference in work load between the diseased and healthy subjects. Those who had occupational skin diseases used protective gloves
Table 6. Diagnosis of occupational skin and respiratory diseases among the clinical study group of the hairdressers. $(A=$ asthma, $\mathrm{APS}=$ ammonium persulfate, $\mathrm{AR}=$ allergic rhinitis, $N R \mathrm{~L}=$ natural ruber latex proteins, $L=$ laryngitis, $P P D A=$ paraphenylenediamine, $A C D=$ allergic contact dermatitis, $P S=$ permanent-wave solutions, $I C D=$ irritant contact dermatitis, $W W=$ wet work, $C U=$ contact urticaria)

\begin{tabular}{|c|c|c|c|c|c|c|}
\hline $\begin{array}{l}\text { Case } \\
\text { number }\end{array}$ & $\begin{array}{c}\text { Age } \\
\text { (years) }\end{array}$ & Atopya & $\begin{array}{c}\text { Duration of } \\
\text { occupation } \\
\text { (years) }\end{array}$ & $\begin{array}{c}\text { Exposure } \\
\text { (years) }\end{array}$ & Diagnosis C & $\begin{array}{c}\text { Causative } \\
\text { agent }\end{array}$ \\
\hline 1 & 45 & + & 25 & 10 & A & APS \\
\hline 2 & 28 & + & 10 & 8 & $A, A R$ & APS \\
\hline 3 & 36 & - & 15 & 12 & AR & APS \\
\hline 4 & 48 & - & 30 & 15 & A/AR & PS,APS \\
\hline 5 & 55 & + & 34 & 14 & $A R$ & APS \\
\hline 6 & 30 & + & 13 & 11,13 & $A R, I C D$ & APS \\
\hline 7 & 34 & + & 8.5 & 4 & $\mathrm{AR}$ & APS \\
\hline 8 & 23 & + & 5 & 4 & $\mathrm{~L}$ & APS \\
\hline 9 & 47 & - & 21 & 9 & ACD & PPDA \\
\hline 10 & 34 & + & 15 & $4.5,4.5$ & ACD,ICD PI & PPDA,WW \\
\hline 11 & 24 & + & 3.5 & 0.5 & $A C D$ & APS \\
\hline 12 & 29 & + & 10 & 2 & $\mathrm{CU}$ & APS \\
\hline 13 & 42 & + & 23 & 2 & $\mathrm{CU}$ & $N R L$ \\
\hline 14 & 26 & + & 4.5 & 2.5 & $\mathrm{ICD}$ & WW \\
\hline 15 & 48 & + & 30 & 20 & ICD & WW \\
\hline 16 & 37 & - & 15 & 13 & ICD & WW \\
\hline 17 & 48 & - & 30 & 22 & KOILONYCHIA & A PS \\
\hline
\end{tabular}

more regularly. However, all of them used gloves during hair dyeing, more than a half used them while giving permanents, and $11 \%$ also used them when washing hair.

Previously diagnosed atopic diseases increased the risk for occupational skin or respiratory disease by 3-fold (OR 2.9, 95\% CI 1.1-7.9). Three years after the diagnosis 1 hairdresser had taken another job, 3 were in retraining, and 1 had retired due to an occupational disease ( 1 case was not traceable). The rest $(\mathrm{N}=11)$ were still working as a hairdresser. Only 1 hairdresser diagnosed as having occupational rhinitis did not have symptoms at work. She was able to avoid exposure to the causative agent (ammonium persulfate). The others had managed to continue in spite of respiratory and skin symptoms by improving the ventilation, using protective gloves regularly, and replacing the chemicals by less irritative and dusty (bleaches) compounds. The insurance companies had accepted $87 \%$ (13 of 15) of the diagnosed occupational diseases. One case of irritant contact dermatitis and the case of koilonychia were not accepted. Two hairdressers did not have insurance.

\section{Discussion}

The participation rate was satisfactory both for the telephone interviews and for the clinical studies, and it was 
therefore possible to extrapolate the results to the complete study population. It is possible that we lost some of the cases of occupational skin and respiratory disease among the nonparticipants. However, selection bias was not likely to be great because the skin and respiratory symptoms among the nonparticipants did not differ markedly from the clinical study group and no occupational diseases were found to be registered for them. If there was a bias, the prevalences of occupational diseases would have been more likely to be underestimates than overestimates.

In the present study, the prevalence of occupational dermatoses (280/10 000) was high and in the same range as the annual prevalence of occupational dermatoses among hairdressers in Germany (244/10 000) (7). If only the dermatoses of specific allergic origin are included, the prevalence of occupational dermatoses $(55 / 10000)$ is only slightly higher than the reported number of cases in the Finnish register of occupational diseases $(20-40$ / $10000)$.

Although work-related respiratory symptoms were common among the hairdressers, specific occupational allergies and diseases were rare; for example, only $4 \%$ (6 or 137) of the hairdressers had a specific cause verified that warranted the diagnosis of occupational rhinitis. A similar relation was seen between the symptoms of the lower respiratory tract and the diagnosed occupational laryngitis and asthma. Methodological reasons may partly explain the results. We cannot be sure that the methods, substances, and their concentrations in the challenge tests were optimal. There is some indication of such possibilities. Permanent-wave solutions caused a significant delayed asthmatic reaction in a lung challenge test, but no immediate reactions were detected with ammonium thioglycolate in the nasal challenge tests.

Because the study closely followed the routine used in the Finnish Institute of the Occupational Health, it also serves as a benchmark for the system used for identifying occupational skin and respiratory diseases $(21,22)$. Altogether $85 \%$ (18 of 21) of the occupational diseases were new cases. A diagnosis of occupational disease was the most probable for the women who had skin symptoms; $20 \%$ ( 11 of 54 ) of these hairdressers received a diagnosis of occupational skin disease.

In 1994 and 1995, the study increased the number of new cases of occupational disease among hairdressers in the Finnish register of occupational diseases by $20 \%$. Even though some of the new cases would have emerged later, the result shows a marked underdiagnosis of occupational skin and respiratory diseases for hairdressers. A similar trend has been noted also with other occupations; for example, Roto et al concluded that only one-third of the cases of occupational hand dermatitis among construction workers are reported to the register of occupational diseases in Finland (24).
In Finland many hairdressers are self-employed persons for whom insurance for occupational diseases is voluntary, and therefore they may tend not to attend occupational medical examinations. Self-medication is common. The computer-assisted telephone interview used in our study revealed that only half of the subjects had consulted a general practitioner or dermatologist because of their hand eczema. In the clinical studies, 9 suspected cases of occupational eczema were found in the group of hairdressers reporting only respiratory symptoms. It seems evident that hairdressers underrate hand eczema and consider it a natural part of their occupation. This possibility may partly explain the low annual prevalence $(13.8 \%)$ of hand eczema found in this study when the results are compared with those of other studies (25).

Ammonium persulfate - an active ingredient in bleaching products - caused $55 \%$ of the diagnosed occupational skin and respiratory diseases. Both immediate and delayed reactions were detected. Together with hair sprays, it was also subjectively the most annoying agent in the hairdressers' work environment, particularly worsening the respiratory symptoms. It is difficult to comprehend why the use of ammonium persulfate still persists in the hairdressing trade, although its side effects have been known for decades (26).

In the records of dermatology clinics, ammonium thioglycolate and glycerylmonothioglycolate in permanent solutions and PPDA in hair dyes are the leading causes of occupational hand eczema among hairdressers in Europe (25). In our study, however, only 2 cases of allergic eczema due to exposure to PPDA and a rare case of koilonychia caused by thioglycolates in permanent-wave solutions were diagnosed (27). Good hand protection during hair dyeing may explain the low prevalence of allergy to PPDA and other colorants. Contrary to our expectations, we did not find sensitization to thioglycolates, although, despite the appearance of hand eczema, nearly a half of the subjects still continued to give permanents without using gloves. Gloves of natural rubber latex were used rarely, and only 1 case of contact urticaria was diagnosed. It seems that, in Finland, educational campaigns about the allergy risk of natural rubber latex gloves have reached hairdressers well.

Allergy to nickel sulfate (31.5\%) and cobalt chloride (13\%) was common. The rates were higher than those of the general Finnish population, but they do not differ from what has been found in other countries among hairdressers and in the younger age groups in these populations $(28,29)$. Nickel may be released from the metal utensils used in hairdressing, but it is unlikely to explain the difference totally $(30,31)$. Selection is a more probable explanation. The hairdressing trade attracts young people who like to use jewellery and already have a nickel allergy, usually contracted when their ears have been pierced for the first time (32). 
Interestingly, the hairdressers in our study had markedly more immediate allergic reactions to human dandruff and to a saprophyte fungus, $P$ ovale, present on scalps with dandruff than the nonoccupationally exposed referents did. Allergy to human dandruff has been reported, but it has not been studied in the hairdressing trade before (33). Hairdressers may develop skin and respiratory symptoms when cutting or brushing someone's hair (34). In the nasal provocation tests, dandruff caused rhinitis symptoms, but the results were not consistent with the allergy tests (35). The significance of allergy to human dandruff and $P$ ovale for hairdressers warrants further research.

In our study, atopic diseases in the subject's medical history markedly increased the risk for occupational skin and respiratory diseases. This finding is in agreement with the findings in other studies on hairdressers' dermatitis $(36,37)$. Should these persons be advised against entering the hairdresser's occupation? We feel that this decision should be made on an individual basis considering the type, length, and severity of the symptoms. If a person has active asthma or atopic hand dermatitis, that person is ill-suited to be a hairdresser. This is not so much because of the risk for occupational allergic diseases, of which the person should be advised, but because of the many chemicals used in hairdressing capable of causing skin and respiratory tract irritation. Atopic diathesis alone is not enough categorically to prevent a person from becoming a hairdresser. Good work conditions and practices, the avoidance of contact with the most hazardous chemicals, and personal protection can greatly reduce work-related symptoms and individual risk for occupational diseases and allergies (38). Such a reduction is important considering that, in this study, one-third of the subjects had to give up their job as a hairdresser due to their occupational diseases during the 3-year follow-up period.

\section{Acknowledgments}

This work was supported by a grant from the Finnish Work Environment Fund. The authors thank Dr Mari Antti-Poika of her continuous support during the study, the clinical and laboratory personnel at the Institute of Occupational Health in Helsinki, and Ms Terttu Kaustia for the language revision.

\section{References}

1. Conde-Salazar L, Baz M, Guimaraens D, Cannavo A. Contact dermatitis in hairdressers: patch test results in 379 hairdress- ers (1980-1993). Contact Dermatitis 1995;6:19—23.

2. Von Peters K-P, Frosch PJ, Uter W, Schnuch A, Arnold A, Bahmer $F$, et al. Occupational contact dermatitis in hairdress ers - results of a multicenter study of eight centers of the 'information network of dermatology clinics' in Germany. Dermatosen 1994;42:50-7.

3. Von Gründer K, Lenzen P, Mayser P. Occupational eczema at the department of dermatology and andrology at the university of Giessen 1980-1989 — ten-year follow-up study. Dermatosen 1994:42:100-6.

4. Frosch P, Burrows D, Camarasa JG, Dooms-Goossens A, Ducombs G, Lahti A, et al. Allergic reactions to a hairdressers' series: results from nine European centres. Contact Dermatitis 1993;28:180-9.

5. Guerra L, Tosti A, Bardazzi F, Pigatto P, Lisi P, Santucci B, et al. Contact dermatitis in hairdressers: the Italian experience. Contact Dermatitis 1992;26:101-7.

6. Toikkanen J, Karjalainen A. Ammattitaudit pohjoismaissa v. 1990-92 [Occupational diseases in Nordic countries in 1990-92]. Helsinki: Finnish Institute of Occupational Health, 1995:26-32. Katsauksia, 133. English summary.

7. Diepgen T, Schmidt A, Schmidt M, Fartasch M. Epidemiology of occupational dermatoses in North-Bavaria. Z Hautkr $1991 ; 66: 935-8$

8. Karjalainen A, Keskinen H, Nordman H, Kurppa K. Incidence of reported occupational asthma in Finland 1990-95. In: Proceedings of the 9th International Conference on Occupational Respiratory Diseases, 13-16 October, Kyoto, Japan, 1997.

9. Frey JH. Survey research by phone. 2nd ed. New York (NY): Sage Publication, 1989. Sage Library of Social Research, no 150.

10. Leino T, Tammilehto L, Lunkkonen R. Nordman H. Selfreported respiratory symptoms and diseases among hairdressers. Occup Environ Med 1997:54:452-5.

11. Kanerva L, Estlander T, Jolanki R. Skin testing for immediate hypersensitivity in occupational allergology. In: Menne T, Maibach HI. Exogenous dermatoses: environmental dermatitis. Boca Raton (FL): CRC Press, 1991:103-26.

12. Dreborg S, editor. Skin tests used in type I allergy testing [position paper]. Allergy 1989;44 suppl 10:52-9.

13. Pirilä V. Chamber test versus patch test for epicutaneous testing. Contact Dermatitis 1975;1:48-52.

14. Cronin E. Contact dermatitis. Edinburgh, London, New York Churchill Livingstone, 1980

15. Viljanen A, editor. Reference values for spirometric, pulmonary diffusing capacity and body pletysmographic studies. Scand J Clin Invest 1982;42 suppl 159:1-50.

16. Quanjer H, Tammeling GJ, Cotes JE, Pedersen OF, Peslin R, Yernault J-C. Lung volumes and forced ventilatory flows. Eur Respir J 1993;6 suppl 16:5-40.

17. Sovijärvi A, Malmberg P, Reinikainen K, Rytilä P, Poppius H. A rapid dosimetric method with controlled tidal breathing for histamine challenge. Chest 1993:104:164-70.

18. Burge P. Single and serial measurements of lung function in the diagnosis of occupational asthma. Eur J Respir Dis 1982;63 suppl 123:47-59.

19. Keskinen H, Nordman H. Ammattiastman taudinmääritys [Diagnosis of occupational asthma]. Suom Lääkäril 1981;36:298-304. In Finnish.

20. Yu B, Sawai T, Uehara M, Ishida T, Horiike K, Nozaki M. Immediate hypersensitivity skin reactions to human dander in atopic dermatitis. Arch Dermatol 1988;124:1530-3.

21. Hytönen M, Sala E. Nasal provocation test in the dignostics of 
occupational allergic rhinitis. Rhinology 1996;34:86-90.

22. Sala E, Hytönen M, Tupasela O, Estlander T. Occupational laryngitis with immediate allergic or immediate type specific chemical hypersensitivity. Clin Otolaryngol 1996;21:42-8.

23. SAS Institute. SAS/STAT: user's guide, version 6.4 ed, volume 2. Cary (NC): SAS Institute, 1990.

24. Roto P, Sainio H, Reunala T, Laippala P. Addition of ferrous sulfate to cement and risk of chromium dermatitis among construction workers. Contact Dermatitis 1996;34:43 - 50.

25. Pilz B, Frosch P. Hairdressers' eczema. In: Menné T, Maibach HI, editors. Hand eczema. Boca Raton (FL): CRC Press, 1994:179-88.

26. Pepys J, Hutchcroft BJ, Breslin ABX. Asthma due to immediate chemical agents - persulfate salts and henna in hairdressers. Clin Allergy 1987;6:399-404.

27. Alanko K, Kanerva L, Estlander T, Jolanki R, Leino T, Suhonen R. Hairdresser's koilonychia. Am J Contact Dermatitis 1997;8:177-8.

28. Peltonen L, Terho P. Nickel sensitivity in school children in Finland. In: Frosch P, Dooms-Goossens A, Lachapelle J, Rycroft R, Scheper R, editors. Current topics in contact dermatitis. Heidelberg: Springer Verlag, 1989:184-7.

29. Gall H, Hutter $J$, Kaufman R, Seidel H-J. Epikutantest-Ergebnisse in Frauenberuffen. Dermatosen 1997;45:160 - 4.

30. Basketter D, Briatico-Vangosa G, Kaestner W, Lally C, Bontinck W. Nickel, cobalt and chromium in consumer products: a role in allergic contact dermatitis? Contact Dermatitis 1993;28:15-25.

31. Diepgen TL, Schmidt A, Pilz B, Ghane Y, Frosch PJ, Fartasch M. Atopy, metal-sensitivity and work-related contact dermatitis in hairdressers - a prospective cohort study. In: Abstracts of the Second Congress of the European Society of
Contact Dermatitis, Barcelona. Barcelona: ESCO, 1994:58.

32. Van der Burg C, Bruynzeel D, Vreeburg K, von Blomberg B, Scheper R, et al. Hand eczema in hairdressers and nurses: a prospective study, I: evaluation of atopy and nickel hypersensitivity at the start of apprenticeship. Contact Dermatitis 1986;14:275-9.

33. Hampton $S$, Cooke $R$. The sensitivity of man to human dander, with particular reference to eczema (allergic dermatitis). J Allergy 1941;13:63-76.

34. Leino T, Nordman H, Kanerva L. Human dandruff as a cause for occupational allergy? In: Finnish Institute of Occupational Health. Abstracts of the 44. Nordic Work Environment Meeting; 1995 Aug 27-29; Naantali, Finland. Helsinki: Finnish Institute of Occupational Health, 1995:224.

35. Hytönen $\mathrm{M}$, Leino $\mathrm{T}$, Sala $\mathrm{E}$, Kanerva L, Malmberg $\mathrm{H}$, Tupasela $O$. Nasal provocation test in the diagnostics of hairdressers' occupational rhinitis. Acta Otolaryngol Suppl (Stockh) 1997;529:133-6.

36. Smit HA, van Rijssen A, Vandenbroucke JP, Coenraads PJ. Susceptibility to and incidence of hand dermatitis in a cohort of apprentice hairdressers and nurses. Scand J Work Environ Health 1994;20:113-21.

37. Uter W, Gefeller O, Schwanitz HJ. The influence of skin sensitivity (atopy) and skin protection on the development of hand eczema in hairdressers - first results of a prospective cohort study. Allergologie 1995;18:312-5.

38. Scmidt U, Schwanitz HJ. Dermatosen bei Auszubildenden des Friseurhandwerks in Niedersachsen: ein Vergleich zwischen 1989 und 1994. Dermatosen 1997:45:121-5.

Received for publication: 12 September 1997 